\title{
SOBRE EL DESARROLLO Y LA DISTRIBUCIÓN GEOGRÁFICA DEL MOTIVO DE "LA MISTERIOSA AMA DE CASA" (N 831.1) EN LA TRADICIÓN ORAL INDOAMERICANA
}

\author{
Enrique Margery Peña
}

\begin{abstract}
This article studies the development and geographical distribution of the Mysterious Housekeeper motif in the indoamerican oral tradition.
\end{abstract}

\section{Preliminares}

El motivo clasificado como N 831.1 en el Motif-Index de Stith Thompson corresponde al denominado "Mysterious Housekeeper" ('La misteriosa ama de casa'). La descripción que Thompson hace de este motivo es la siguiente: Un hombre encuentra su casa puesta misteriosamente en orden. Descubre que la autora del hecho es una muchacha (frecuentemente, un animal transformado en muchacha). Luego, el autor cita una bibliografía atingente a la existencia de esta unidad narrativa en el folklore de Italia, India, China, Corea, Indonesia, Malasia, Filipinas, Norteamérica, Surinam, y en etnias africanas de Basuto y el Congo.

En lo que respecta a consideraciones y estudios sobre este motivo en Indoamérica, ámbito específico de este trabajo, cabe en estos Preliminares mencionar a dos investigadores. El primero de ellos es el propio Thompson quien en la nota 207 de su Tales of North American Indians, y a propósito de un relato cree que aquí consideraremos, cita la presencia de este motivo en narraciones de otras cinco etnias de Norteamérica, a saber: kodiak, lillooet, kwakiutl, iroquesa y seneca.

La segunda referencia se relaciona con el artículo de Fernando Horcasitas "An analysis of the Deluge Myth in Mesoamerica", escrito en 1953 y que conocemos por su inclusión en la obra de Alan Dundes (1988) que recopila diversos estudios sobre este mito.

Sobre este último artículo - del que aquí haremos reiteradas referencias- cabe señalar que en él, el investigador mexicano fija el motivo de "la misteriosa ama de casa" como uno de los cinco tipos que según este autor concurren en más de una treintena de versiones sobre el mito del diluvio registradas en distintos pueblos de Mesoamérica. No obstante, dado que en las versiones consideradas, el motivo de "la misteriosa ama de casa" se asocia reiteradamente con 
la historia de la "esposa-perro" -ya que en ella el animal transformado en mujer corresponde a esta especie y termina casado con el beneficiario - el estudio de Horcasitas se orienta a demostrar que esta última historia parece ser, con algunas variantes, originaria del continente americano.

En lo pertinente a este trabajo, las versiones de este motivo que hemos recopilado, sumadas a las que aporta Horcasitas en el artículo recién mencionado, configuran un corpus de relatos cuyo examen y cotejo permiten determinar algunas características de los relatos en los que se presenta el motivo de "la misteriosa ama de casa", posibilitándose, a la par de ello, esbozar algunos lineamientos concernientes a la distribución geográfica que en el ámbito indoamericano ofrecen sus distintas manifestaciones.

\section{Funciones del motivo de "la misteriosa ama de casa" en los diversos relatos que lo contienen}

En lo referente a las relaciones que se establecen entre el motivo y el contenido general de cada relato, cabe distinguir dos tipos de textos: aquellos en los que el contenido integral de la narración se reduce, con mayor o menor extensión, a los acontecimientos dispuestos en el motivo, y aquellos en los que el motivo de "la misteriosa ama de casa" constituye en episodio inserto en el desarrollo, de suyo más amplio, de un determinado mito. A su vez, en este segundo tipo de relatos debe hacerse una necesaria distinción entre las narraciones cuyos contenidos míticos más amplios comportan elementos que no se vinculan con los componentes del motivo de "la misteriosa ama de casa", y los relatos en los que sí se aprecia claramente esta vinculación.

Seguidamente expondremos los principales elementos concurrentes, así como las variantes de más relevancia, correspondientes a estos tres órdenes de relatos.

\subsection{Relatos cuyo contenido corresponde al desarrollo del motivo de "la misteriosa ama de casa"}

En sus manifestaciones narrativas, el motivo se ajusta a un esquema bastante simple: un hombre solitario descubre al regresar a su casa que alguien ha realizado ciertas tareas domésticas y le ha preparado la comida. Se trata, en realidad, de un animal que adopta una forma humana para hacer estas labores. Sorprendido por la reiteración de este hecho, el hombre se oculta y percibe la presencia de una mujer. Sale, entonces, de su escondite y sorprende en el interior de la vivienda a la misteriosa ama de casa. Ella no recobra su forma original y se queda en el lugar como esposa del hombre.

Con algunas variantes de este esquema - las cuales luego examinaremos - este desarro1 lo lo hemos encontrado en siete relatos originados en distintos lugares del Continente. A continuación nos referiremos a estas versiones, reseñando brevemente sus respectivos contenidos.

En lo que respecta a la América del Norte, dos relatos de procedencia esquimal refieren sendas versiones de la "historia de la mujer zorro". El primero de estos relatos corresponde a "The Fox-Woman" (' La mujer-zorro' ), recogido entre los esquimales de la Península del Labrador por Lucien Turner (en S. Thompson 1929/1967: 161-162). Su desarrollo es bastante simple: Un cazador solitario encuentra repetidamente a su regreso, sus ropas ordenadas y deliciosos 
alimentos preparados. Sorprendido por esto, un día se oculta para vigilar la entrada de la casa. Al rato ve entrar a un zorro, y creyendo que el animal va tras la comida, sale de su escondite y entra en la vivienda. Encuentra en ella una hermosa mujer y, colgada de una cuerda, la piel de un zorro. La mujer le dice que ella es su esposa y, como tal, se queda junto al hombre. Pasado poco tiempo, éste comienza a percibir en la casa un fuerte olor a almizcle y le pregunta a su mujer si ella sabe qué es aquello. La mujer responde que es ella la que despide tal olor, y tras decir esto, destroza sus ropas, y cogiendo la piel de zorro, abandona la casa sin regresar jamás.

La otra versión de esta historia se halla en el relato "The man who married a fox" ("El hombre que se casó con un zorro' ), que Knud Rasmussen obtuvo a inicios de este siglo entre los esquimales del este de Groenlandia (en: H. Norman 1990: 323-324). Se trata de un relato algo más extenso que el anterior y cuyo contenido es el siguiente: Un hombre soltero caza una zorra y la lleva a su casa. Le hace un sitio bajo la ventana donde le arroja huesos como a un perro. Cuando el hombre regresa de cazar, ve que las pieles de las focas están secas y tendidas, que la lámpara está encendida y que la olla hierve en el fuego. Sorprendido, se oculta y descubre que quien hace todas estas labores es una hermosa mujer. Al día siguiente, entra tras ella a la casa y la coge antes de que ella logre llegar hasta bajo la ventana para transformarse de nuevo en zorra. Convertida en mujer, ella permanece como esposa del hombre, siendo lo único que revelaba su origen el fuerte olor a zorro cuando sudaba. Cierto día llega a la casa un extraño que le propone al hombre intercambiar esposas. Tras varias negativas éste acepta. El extraño se lleva a la mujer-zorro, pero cuando ella empieza a sudar, él se queja del mal olor. La mujer, entonces, lanza un aullido y escapa convertida en zorro.

En el Area de Mesoamérica, F. Horcasitas (1953/1988: 207) cita una versión popoluca, pueblo de filiación mixe-zoque, obtenida por George Foster. Su contenido es el siguiente: Después de la muerte de su esposa, un hombre queda muy triste y solo en compañía de su perro. A partir de entonces, al volver a su casa, el hombre encuentra tortillas frescas y otros alimentos preparados. Un día regresa más temprano y sorprende a una hermosa mujer cocinando tortillas, y muy cerca de ella, colgada, la piel del perro. El hombre se casa con la mujerperro.

El mismo Horcasitas (íbidem.: 210) transcribe un relato caribeño recogido por Douglas Taylor ${ }^{1}$. En él se refiere que un viudo que vivía con su perra, al regresar a su casa encontraba que alguien había preparado comida y había ido en busca de leña y agua. Un chismoso le dijo que en realidad era la perra la que hacía todo esto, y que si él quería que la perra se quedara como mujer, debía llevarla al río, sumergirla en el agua y hacer que un pez le pasara por entre las patas. El hombre así lo hizo y la perra se convirtió en mujer. Sin embargo, al tiempo, cansado de la esposa perro, el hombre la llevó de nuevo al río y la volvió a convertir en perra para siempre.

Las tres versiones restantes que desarrollan el motivo con estas características proceden de Sudamérica: dos de ellas del Area Amazónica ${ }^{2}$ y la tercera de la denominada Area del Este del Brasil.

La primera de las versiones amazónicas corresponde a un relato citado por H.B. Alexander (1920/1964: 274) como obtenido en Surinam, aunque este autor no precisa si su origen es arahuaco o caribe. Los acontecimientos narrados en esta versión son los siguientes: Un 
anacoreta tenía un perro asombrosamente fiel. Caminando por el bosque, descubrió cierto día un campo cultivado de yuca y otras plantas comestibles. El se ocultó para descubrir quien era su benefactor, y vio entonces llegar a su perro que, desprendiéndose de su piel, se convertía en una mujer y se ponía a trabajar. Otro día, él nuevamente se ocultó, y cuando apareció el perro, sigilosamente le robó la piel y la quemó. Tras esto, el perro quedó convertido en mujer y terminó siendo su esposa y madre de una numerosa familia.

La segunda versión amazónica es la titulada "La gente cigüeñas jabirú", recogida por Lux Vidal entre los shikrin, un pueblo de filiación gê que habita en las proximidades de la margen oriental del Río Xingú, en Brasil. Dada su brevedad, procedemos a continuación a citar nuestra traducción del texto que ofrecen Wilbert y Simoneau (1984: 440-441):

Kamri es una cigüeña jabirú

Dos mujeres cigüeñas jabirú fueron a la plantación y en el camino de regreso a la aldea hicieron un pastel de mandioca.

El dueño de la casa llegó y no sabía quién había hecho el pastel.

Él se ocultó para descubrir quién había hecho los pasteles.

Mientras estaba oculto vio a dos mujeres cigüeñas haciendo los pasteles.

El indio las cogió para criarlas. El les rapó sus cabezas y se las pintó con genipapo, en la forma en que lo hacen las mujeres.

Luego de esto, ellas no volvieron a convertirse en pájaros . No era necesario ir todos los días a pescar para ellas: ellas podían comer de todo.

Ellas se quedaron en la casa como sus hijas y después se casaron con indios.

La tercera versión sudamericana, procedente, tal como se señaló, del Este del Brasil, corresponde al relato bororo "Las dos palomas" (v.1), obtenido por Colbacchini y Albisetti (en Wilbert y Simoneau 1993: 113), y cuyo contenido es el siguiente: Una mujer llamada Birimoddo vivía sola, sin tener a nadie que le preparara comida y que le ayudara en las tareas domésticas. Al volver un día a su casa, halló la olla llena de harina de maíz. Al repetirse este hecho en los días siguientes, la mujer empezó a preguntarse quién podría estar favoreciéndola, ya que cuando salía, sólo quedaban en la choza dos palomas que ella estaba criando. Cierta vez regresó antes de lo acostumbrado y al aproximarse a la casa escuchó voces y risas. Al entrar vio a dos muchachas preparado una sopa de maíz. Al verla, ellas quisieron volver a se estado natural, pero Birimoddo les rogó que no se transformaran en palomas y que se quedaran allí como sus hijas, a lo cual ambas accedieron.

Estas versiones, en su conjunto, motivan algunas consideraciones que estimamos de interés. Así, los contenidos del motivo determinan que la figura del beneficiario de las acciones de "la misteriosa ama de casa" deba corresponder a una persona solitaria -un soltero en las versiones populuca y caribeña, y un anacoreta en la narración arahuaca o caribe. En este paradigma, la variante más significativa se da en el relato bororo en el que es una mujer la que desempeña este rol.

Frente a la relativa uniformidad del personaje beneficiario, la figura de "la misteriosa ama de casa" comporta más variantes, especialmente en lo relacionado con las especies animales que dan origen a esta entidad.

En lo pertinente a este último aspecto, las variantes ameritan tres consideraciones básicas. La primera de ellas consiste en anotar que las versiones esquimales son las únicas en todo el corpus en la que la especie animal es un zorro. La segunda consideración radica en señalar 
que ya en este tipo de relación se aprecia la disyunción "perro(a) / aves" en relación con la especie cuya transformación origina "la misteriosa ama de casa". Sobre los elementos de esta disyunción conviene hacer notar que el relato arahuaco o caribe es el único procedente de Sudamérica, en todo el corpus, en el que esta función la desempeña un perro. Finalmente, la tercera consideración, ligada a la disyunción recién señalada, surge del hecho de que las versiones sudamericanas se caracterizan por la condición dual de las aves que cumplen esta función, lo cual se corrobora en estos relatos por la intervención de las dos palomas en el texto bororo y de las dos cigüeñas jabirú en la narración shikrin.

En cuanto ya a los acontecimientos referidos en estas versiones, cabe señalar que tras el hallazgo del alimento preparado, el episodio de mayor relevancia, merced a las variantes que ofrece, lo constituye la impedida transformación de las mujeres en las especies animales originales.

Con la excepción del relato caribeño, en el cual el beneficiario se entera de lo que ocurre por la intervención de "un chismoso", las restantes versiones plantean primero el acecho y luego la llegada intempestiva del personaje como las acciones que preceden a este hecho. Así, en uno de los relatos esquimales, la mujer no alcanza a llegar al sitio bajo al ventana donde se convertiría en zorra, en tanto que en el texto bororo es la súplica de la mujer la que logra que las muchachas accedan a conservar su forma humana.

Las versiones caribeña y shikrin ofrecen sendas variantes en el desarrollo de este episodio, ya que en ellas la transformación definitiva en mujeres -a pesar de no ser irreversible, en el caso de la primera- se da mediante un ritual, de un orden mágico en el relato caribeño, y consistente primero en raparlas y luego pintarles la cabeza a la usanza de las mujeres, en el caso de la narración shikrin.

Por último, en lo que respecta al relato arahuaco o caribe, el beneficiario se apodera y quema la piel del perro, imposibilitando con ello la transformación de la mujer. Se trata, como se verá más adelante, de un episodio que se reitera en todas las versiones procedentes de Mesoamérica, y cuya existencia en esta narración plantea una dimensión interesante en lo que se refiere a la distribución geográfica de este elemento narrativo.

El otro episodio relevante es el que corresponde al desenlace del esquema básico que ofrecen las distintas versiones. De este modo, en los relatos esquimales, popoluca, caribeño y arahuaco o caribe, "la misteriosa ama de casa" termina convertida en la esposa del beneficiario. Por otra parte, en lo que corresponde a las versiones bororo y shikrin, ellas se cierran con la adopción de las mujeres-aves, no obstante que en el caso de las mujeres-cigüeñas, la narración shikrin refiere que "después ellas se casaron con indios".

\subsection{Relatos en los que el motivo es un fragmento no vinculado temáticamente con los distintos mitos que ellos desarrollan}

En relación con este tipo de relatos haremos referencia a cinco textos, los cuales, como en el caso anterior, se disponen en una amplia distribución geográfica.

Procedente de América del Norte, el primer texto corresponde al relato "Mudjikiwis", recogido entre los cree de las planicies, un pueblo algonquino, por Alanson Skinner (en S. Thompson 1929/1967: 135-145). 
Mudjikiwis es el mayor de los diez hermanos solteros que viven en el campamento. Al regresar un día a su tienda, percibe desde lejos el humo que sale de su interior y leña cuidadosamente apilada afuera. Al entrar, observa huellas de una muchacha partituerta y ve que la comida está preparada, el agua recién traída y diez pares de mocasines nuevos. Luego de que les muestra este prodigio a sus hermanos, éstos se turnan en los días siguientes para ocultarse y sorprender a la misteriosa visitante. Mientras está vigilando el quinto hermano, llega la muchacha y se queda allí como esposa del hombre, hecho que produce la alegría de todos. Cierto día, Mudjikiwis, enamorado de su cuñada, se le insinúa a ésta, y como ella lo rechaza, él la hiere en la pierna con una flecha. Tras este incidente, la muchacha se retira a una tienda apartada y luego desaparece. Su marido, el hermano de Mudjikiwis, inicia en su búsqueda un largo viaje que lo lleva hasta un mundo superior, donde por fin encuentra a su esposa que es una de las diez hijas de los seres tronadores. Tras superar varias pruebas, el hombre regresa con su esposa, acompañado de sus nueve cuñadas las que se casan con sus nueve hermanos.

Conviene aquí anotar que gran parte del extenso relato cree consiste en la narración del viaje del quinto hermano al mundo superior en busca de su esposa, desarrollo mítico en el que no faltan las pruebas que el héroe supera con la ayuda de objetos mágicos que recibe de las sucesivas donantes que va encontrando en su camino.

El segundo y tercer relato proceden, respectivamente, de dos pueblos de origen chibcha del Área Intermedia. En el primer caso, se trata de una narración cuna (Chapman 1989:111116) que refiere la historia de cuatro hermanos que abandonan la casa paterna disgustados con su madre y con su hermana, y asqueados de la comida que ambas les preparan. Con el propósito de que se aprecien los acontecimientos correspondientes al motivo, citamos aquí los párrafos pertinentes de este relato:

"Los hermanos pasaron muchos meses trabajando duramente en la montaña. Una tarde cuando regresaron a casa del campo encontraron comida y bebida en la mesa, todas sus ropas limpias, y la casa barrida, Sintieron un olor fragante en el aire, y cuando probaron la comida vieron que era muy sabrosa (...) Decidieron dejar al más joven en casa al día siguiente para ver quién estaba visitando la casa mientras ellos estaban ausentes.

Temprano, a la mañana siguiente, los tres hermanos salieron para el monte y el más joven se escondió detrás de un palo grande en el patio. En corto tiempo sintió un ruido extraño (...) Vio entonces descender un platillo de oro desde el cielo que aterrizó frente a la casa. Salió una escalera de uno de los costados del platillo y bajaron cuatro lindas muchachas. Entraron a la casa y cada una se dedicó a hacer un oficio especial: una barrió el piso, una cocinó, otra fue al río a limpiar la carne y la otra preparó las bebidas.

Cuando terminaron, desenrollaron las hamacas de los cuatro hermanos y se pusieron a descansar (...) Habían traído con ellas bolsas de algodón crudo con un aparato de hacer hilo, y se pusieron a separar las semillas del algodón y hilar. Estuvieron algún rato absortas en su trabajo cuando una de ellas dijo: "Creo que mejor nos vamos porque los hombres regresarán pronto". Amarraron las hamacas, entraron al platillo de oro y subieron al cielo."

Los acontecimientos subsecuentes a estos hechos son los reiterados en las distintas versiones: en otra ocasión, los cuatro hermanos acechan a las mujeres, y cuando estas están en la 
casa se abalanzan sobre ellas logrando capturar a una, Olonadili, la cual se queda como esposa del hermano menor.

Tras concluir este episodio, correspondiente al motivo de "la misteriosa ama de casa", el relato cuna desarrolla el "mito del origen del canto femenino", luego de referir que desde el cielo baja un pajarillo que se convierte en una niña a la que Olonadili le canta canciones de cuna, y, luego de su muerte, dolidos cantos funerarios, estos últimos con reiterados elementos procedentes del cristianismo.

El segundo de los relatos del Área Intermedia corresponde a un texto cabécar (Margery Peña 1986: 176-178) que refiere el mito del origen del tigre de agua, uno de los espantos zoomorfos que en la tradición de este pueblo castiga el incesto. Dada la brevedad de la narración, citamos a continuación su versión en español:

"Cuando nacieron los primeros humanos, éstos cogieron un día a un perico y lo dejaron en la casa. Y desde entonces comenzó a suceder que a pesar de que no había nadie en la casa cuando ellos salían a trabajar, a su regreso siempre había en la olla comida cocinada, sin que ellos supieran quien la hacía. Un día decidieron ocultarse para saber quién era la persona que cocinaba cuando ellos se iban, y entonces vieron que el perico descendía de lo alto del rancho y, convertido en una mujer, se ponía a cocinar. Al ver esto, salieron de su escondite y, desde entonces, el perico continuó para siempre convertido en mujer y viviendo con ellos en la casa. Pero empezó a suceder que cuando el hombre volvía de su trabajo, su mujer lo esperaba con un pescado cocinado. Hasta que un día el hombre se ocultó para saber cómo ella conseguía los pescados, y entonces vio que un hombre llegaba a la casa con un pescado. En ese momento salió de su escondite y con una flecha hirió al desconocido en la axila; luego lo vio correr y de un salto meterse en el río. Ese fue después el Tigre de Agua."

La cuarta versión del motivo contenida en relatos de este tipo hace necesario un alcance previo. En la tradición oral de varios pueblos gê, como ocurre con los kayapó, los krahó, los apinayé, los sherente, los apanyekra y los ramkokámekras, se reitera con desarrollos muy similares la "Historia de Pud Mbud-ti ('Sol') y Pudelere Mbuduvri-re ('Luna'). Se trata de relatos, por lo común muy extensos, que narran sucesivos acontecimientos en los que ambos personajes -siempre masculinos- participan como los primeros habitantes de la tierra, y en los que se refieren varios "mitos de origen", como, v. gr., el de los seres humanos, el de la diferenciación de las razas, el de los animales, el de las costumbres y sistemas sociales, el de la vida breve, etc.

Precisamente, en la versión de "La historia de Sol y Luna" que procede de la tradición oral apinayé, pueblo de filiación gê asentado en el Área Amazónica, se encuentra un pasaje correspondiente al motivo de "la misteriosa ama de casa".

En el mencionado pasaje de la narración, recogida por Curt Nimuendajú en 1939 (en Wilbert y Simoneau 1978: 51-55) se refiere que, yendo un día de cacería, Sol encuentra un nido con dos crías de loros enanos, los cuales se lleva a la casa, dándole uno a su compañero Luna. Cierta vez, mientras ambos andaban cazando, uno de los loros le dice al otro: "Me da mucha pena nuestro padre. Cuando regresa cansado después de la cacería, tiene que preparar comida para él y para nosotros. Le ayudaremos". Tras esto, los dos loros se transforman en muchachas y mientras una vigila la entrada, la otra se dedica a cocinar los alimentos. En las secuencias que 
siguen a este hecho, citamos nuestra traducción del texto en inglés que se encuentra en Wilbert y Simoneau:

Cuando Sol y Luna venían de regreso, escucharon a lo lejos el sonido de un mortero que súbitamente cesó. Cuando entraron a la casa, encontraron la comida preparada y a los dos loros que, como de costumbre, estaban encaramados en su palito. Ellos descubrieron huellas humanas, pero, para su asombro, sólo dentro de la casa y no en el camino. Esto continuó por varios días. Por último, Sol le dijo a su compañero: "Ocultémonos en los arbustos y tan pronto oigamos el ruido del mortero, cada uno correrá hacia una de las dos puertas". Así, partieron a sus escondites y pronto escucharon dentro de la casa ruido de risas y de conversaciones. Al oir el sonido del mortero, ambos corrieron y simultaneamente entraron por las dos puertas. Las muchachas dejaron caer sus piedras de moler, bajaron sus cabezas y se sentaron. Eran hermosas, de piel clara., y sus cabellos les llegaban hasta las rodillas (...)

Tras este encuentro, el episodio finaliza refiriendo que las dos muchachas se quedan en la casa, conviviendo una con Sol y la otra con Luna.

Por último, una quinta versión insertada también episódicamente, nos remite a un relato bororo (v.2) que, aunque muy similar al texto de esta procedencia descrito en 1.1 (v.1), es por su carácter de episodio incrustado en la narración de un mito mayor, ubicable entre las versiones aquí incluidas.

Se trata de un texto recogido por Albisetti y Venturelli, que en la edición de Wilbert y Simoneau (1983: 114-116) lleva por título "The Metúgoe Doves and the Indian Magureréu" ('Las palomas metúgoe y el indio Magureréu').

En el inicio del relato, Magureréu invita a su amigo Aróro Idáre a una cacería, advirtiéndole que no debe probar alimentos en el camino. Aróro desoye la advertencia y, por ello, pierde su cuerpo, en tanto que su cabeza comienza rodar tras los pasos de Magurreréu. Así, inserto en la narración de "el mito de la cabeza rodante"3, se encuentra el episodio de "la misteriosa ama de casa", cuyo desarrollo es el siguiente:

Magureréu encuentra un nido con dos crías de palomas métugoe y se lo lleva a su choza. Un día, antes de salir, mira sus abundantes provisiones y exclama: “`Si sólo tuviera una esposa que me preparara una sopa de maíz!". A su regreso, encuentra una olla con una fragante sopa. Al repetirse aquello, Magureréu comienza a sospechar de las palomas. Entonces, diciéndoles a éstas que no salieran, finge irse y, oculto en un arbusto se pone a observar la choza. De improviso, escucha el sonido del metate, risas y la voz de una mujer diciendo: "Amiga mía, apúrate porque tu futuro esposo volverá pronto". Luego de esto, ve salir, camino al río, a dos bellas muchachas. Magureréu entra en la choza y observa la olla en el fogón. Al mirar en el nido, ve que en él sólo hay dos pellejos cubiertos de plumas. Pensando quedarse con las muchachas, coge los pellejos y los arroja al fuego. Cuando la mujeres regresan, agarra a una y les ruega que se queden con él y sean sus esposas, a lo cual ellas acceden.

Luego de referir, tras este cierre, que las palomas pertenecían al clan Aroróe y que por este hecho los miembros del subclan de Magureréu adquirieron el derecho de casarse con los Aroróe, el relato prosigue con la narración del mito de la cabeza rodante. 
Estas versiones que constituyen episodios fragmentarios en al narración de determinados mitos, motivan algunos alcances que estimamos de interés. Uno de estos alcances radica en hacer notar que en las versiones cree y cuna, los contenidos del motivo de "la misteriosa ama de casa" quedan claramente desdibujados por la ausencia del episodio de la transformación de especies animales en mujeres, que es, al parecer, uno de los elementos fundamentales del esquema básico del motivo. Además, la mención del platillo de oro que en el relato cuna conduce a las mujeres desde el cielo hasta la tierra, introduce un objeto maravilloso que no se encuentra en otros textos referentes a este motivo que hasta la fecha hemos recopilado. Otro alcance consiste en señalar que en estos relatos se confirma lo ya anotado en el sentido de que en las versiones originadas en Sudamérica -con excepción del relato arahuaco o caribe (véase 1.1)- las especies animales que se transforman en "la misteriosa ama de casa" son invariablemente aves y siempre de carácter dual, tal como se aprecia en los dos loros enanos de la narración apinayé y en las dos palomas metúgoe del relato bororo, en contraste con la figura singular del perico en la versión cabécar, procedente esta última del Área Intermedia.

Finalmente cabe señalar que el relato bororo plantea un elemento de interés cuando Magureréu quema los pellejos con plumas de las palomas, haciendo con ello irreversible la transformación de las aves en mujeres. Lo relevante de este episodio es que se trata de un incidente reiterado en los textos originados en Mesoamérica, en tanto que fuera de este ámbito sólo aparece en el relato arahuaco o caribe, procedente de Surinam, en el pasaje del texto bororo aquí incluido, y en la versión bribri, del Área Intermedia (véase 1.3.1.).

\subsection{Relatos que desarrollan mitos vinculados con el motivo de "la misteriosa ama de casa"}

Por último, corresponde hacer referencia a los relatos que desarrollan contenido míticos temáticamente vinculados con el esquema básico de "la misteriosa ama de casa". Se trata de textos que implican estructuras relativamente complejas en las que el motivo posee una función relevante en relación con le significado integral del relato.

En este plano, cabe, en lo temático, distinguir dos subtipos de narraciones: aquellas en las que el motivo se vincula con "el mito del origen de un clan" y aquellas en las que el motivo opera en función del "mito del repoblamiento del mundo después de un cataclismo", temática esta última donde se agrupa una gran cantidad de relatos de nuestro corpus.

\subsubsection{Relatos en los que el motivo de "la misteriosa ama de casa" se vincula con el "mito del origen de un clan"}

La vinculación entre el motivo de "la misteriosa ama de casa" y el mito del origen de un clan o subclan, la hemos encontrado en un relato bororo (v.3) y en uno bribri, pueblo chibcha del Área Intermedia asentado en el sudeste de Costa Rica.

En lo que respecta al texto bororo, recogido por Albisetti y Venturella (en Wilbert y Simoneau 1983: 112), debe señalarse que se trata de una variante de v.1.: Una mujer solitaria cría 
en su choza dos palomas metúgoe. Estas comienzan a transformarse en dos muchachas que día a día le preparan una olla de mazamorra de maíz. Cierta vez, la mujer se oculta y entra súbitamente a la choza sorprendiendo a las muchachas a quienes, después de tranquilizarlas, les ruega que se queden con ella como si fueran sus hijas. Tras de este hecho, el relato finaliza en los término siguientes:

Así tranquilizadas, las palomas decidieron quedarse en la casa de la pobre mujer. Más tarde se casaron y tuvieron muchos hijos de los que descienden algunos miembros del subclán Aróroe Cebegiwuge. A causa de esta descendencia, los Aróroe Cebegiwuge consideran a las metúgoe entre sus totems.

Tal como se aprecia, el contenido de esta versión es similar al del relato de este mismo pueblo (v.2) citado en 1.2., con la diferencia de que en aquel se trataba de un fragmento inserto en el mito de la cabeza rodante, en tanto que en esta última versión, el motivo se cierra con la mención del origen del citado subclán.

En cuanto al relato bribri, este corresponde a un texto recogido por Cubero Venegas (en Bozzoli de Wille, C. Cubero Venegas y A. Constenla Umaña, s.f.: 5) que a continuación reproducimos:

"En un ranchito vivía un señor y su único compañero era una lorita o chucuyo; él siempre trabajaba, pero no tenía compañera que le hiciera los quehaceres domésticos, pero un día topó con la sorpresa que al regreso del trabajo encontró todos los alimentos preparados y esto se repitió por varias ocasiones hasta que un día tuvo la curiosidad de ocultarse en un rincón de la casa y el chucuyo que dejaba afuera en un palo se bajó y entró a la casa y se sacudió dejando caer todas sus plumas y se transformó en una hermosa muchacha que empezó a cocinar. Él la observaba por largo rato; el chucuyo volvió al lugar donde había dejado las plumas, se emplumó y se convirtió en chucuyo y volvió al palo. Él pensó que esa muchacha le podía servir de esposa y decidió quedarse por segunda vez como el día anterior para robarle las plumas, lo cual sucedió tal como lo había pensado. Salió, robó las plumas y las echó fuego.

A la muchacha le dolió esta acción del hombre, pero él le dijo que no se preocupara y que se casara con él, pues él vivía solo y ella aceptó la proposición y se quedaron viviendo allí.

Pero a la muchacha le quedó el pico del chuchyo detrás de la cabeza. Esta pareja tuvo muchos hijos. Cuando los hijos estuvieron grandes, la madre les decía a los hijos que le buscaran piojos. Ella lo hacía con el propósito de preguntarles qué tenía detrás de la cabeza, pero los hijos nunca le respondieron porque habían sido aconsejados por el padre, pues si no ella se iría y jamás regresaría. Por esta razón los hijos nunca le dijeron qué tenía en la cabeza.

Un día, el hijo menor que no sabía nada al respecto, le dijo que ella tenía un pico de chucuyo y de inmediato ella subió volando como un chucuyo con el hijo hacia una laguna, hacia el este, donde sale el sol. Así quedó formado el distsöwö o clan llamado Kötsöbawa".

El contenido de estos dos relatos motiva dos consideraciones de interés. La primera consiste en anotar que la versión bororo (v.2) y esta narración bribri son la únicas manifestaciones 
del motivo en las que el beneficiario "quema" las plumas de las aves originarias de "la misteriosa ama de casa”, suceso éste que se reitera en relación con la piel en las versiones en las que tal entidad corresponde a la figura del perro.

La segunda consideración se refiere a que en la versión bribri, tal como acontece en los relatos de procedencia esquimal, se aprecia la existencia del motivo C 441 , al que Thompson (1929/1966: 342, n. 234) denomina "el tabú de origen", y que consiste en la prohibición de mencionar la forma original de una persona o cosa transformada. Así es la transgresión de este tabú la que determina la transformación en zorra y la inmediata huida de la esposa en las versiones esquimales, así como el vuelo sin retorno de la mujer chucuyo en el relato bribri.

\subsubsection{Relatos en los que le motivo de "la misteriosa ama de casa" se vincula con el "mito del repoblamiento del mundo después de un cataclismo"}

En este tipo de relatos se agrupan quince versiones, nueve de las cuales, correspondientes al Área de Mesoamérica, las hemos obtenido del artículo de Fernando Horcasitas (19531988) sobre el mito del diluvio en Mesoamérica.

En su conjunto, esto relatos plantean un desarrollo bastante similar, consistente en el que de un cataclismo que destruye la humanidad, escapan uno o dos hombres. La transformación de determinadas especies animales (aves o un perro) en mujeres, tras el consiguiente episodio de "la misteriosa ama de casa", posibilita su unión con el o los supervivientes y, con ello, el repoblamiento del mundo.

En este marco, el cataclismo lo constituye el Diluvio o la Gran Inundación, con excepción de la versión Karaja, un pueblo de filiación gê asentado en el Área del Este del Brasil, en el que tal acontecimiento corresponde al Gran Incendio del Mundo. Así, el texto karaja, recogido por Herbert Baldus (en Dick E. Ibarra Grasso 1980: 133), refiere:
"Nada quedó con vida después del Gran Incendio del Mundo sino dos periqui- tos en la casa de los viejos, y dos rapazuelos que se habían escondido. Los peri- quitos cada día pilaban maíz y cocinaban. Los muchachos pusiérionse en ob- servación. Vieron que los periquitos eran unas mozuelas ya adultas. Los rapa- ces eran todavía pequeños. Cuando se hicieron hombres, se casaron con los pe- riquitos y tuvieron muchos hijos. Todos los hijos de ellos son karajás."

Conforme a lo ya señalado en lo que respecta a las versiones originadas en Sudamérica, en el relato karaja intervienen dos aves, en este caso dos psitaciformes, que dan origen a la figura dual de "la misteriosa ama de casa". De igual manera, y como una constante en los relatos de este tipo, el "mito del repoblamiento del mundo" se plantea de un modo etnocéntrico con respecto del pueblo a cuya tradición corresponde el texto.

También en Sudamérica, estas características se aprecian en lo que se refiere al Área Amazónica, en la versión jívara, que Federico González Suares publicara en 1904 en su Prehistoria Ecuatoriana, y de la que a continuación citamos nuestra traducción del texto que se halla en Stirling (1938: 122): 
En la época en que se produjo el diluvio, dos hermanos escaparon refugiándose en una alta montaña que estaba por encima del nivel de la inundación. Cuando las aguas bajaron, ellos descendieron en busca de seres vivientes, pero no tuvieron éxito y decidieron que ellos eran los únicos sobrevivientes. Al volver a su refugio, se sorprendieron al encontrar fuentes con alimentos. Para aclarar el misterio, uno de los hermanos se ocultó y vio entrar a la choza dos loros en forma de mujeres que prepararon la comida. Saliendo de su escondite, él cogió a uno de los pájaros y se casó con ella y de este matrimonio nacieron tres niños y tres niñas que fueron antepasados del pueblo jívaro.

Finalmente, en lo que respecta a las áreas culturales propiamente sudamericanas, cabe hacer mención en el Área Peruana de la versión maina, pueblo de genealogía no clasificada que habitó en el extremo norte de Perú hasta su extinción a mediados del presente siglo. Se trata, en este caso, de una de las escasas muestras de la tradición oral de esta etnia, publicada a fines del siglo pasado por Jiménez de la Espada ${ }^{4}$ y que aquí citamos siguiendo la referencia de Steward y Métraux (1948: 649). Lo singular de esta versión es la sentencia humorística que cierra la manifestación del motivo, dejando con ello implícita la referencia al repoblamiento del mundo:

Una inundación provocada por el lago Rimachuma destruyó a la humanidad, excepto a un hombre que vivía en una choza donde él comenzó a encontrar todos los días alimentos preparados. Descubrió que los alimentos provenían de dos loros, que volaban hasta su casa convirtiéndose allí en mujeres, siendo una la patrona y la otra, la sirvienta. El se casó con la patrona, y de allí que las mujeres hasta hoy son perezosas.

En lo que corresponde al Área Intermedia, este orden de relatos se encuentra representado por el mito cañarí recogido por Bernabé Coto en la Provincia de Cañaribamba, diócesis de Quito, y publicado por este cronista en su Historia del Nuevo Mundo (Madrid: 1613-1639).

Creemos importante acotar que el ya extinto pueblo cañarí, de marcada influencia quechua, se asentaba en el extremo sur del Área Intermedia, circunstancia esta que determina, como en este caso, que sus tradiciones presenten rasgos propios de las culturas sudaméricanas. Con el propósito de ilustrar documentalmente este trabajo, citamos a continuación gran parte del texto de Coto, según aparece en Jesús Lara (1973: 55-57):

"(...) cuentan que se salvaron del Diluvio dos mancebos hermanos en un monte alto que hay en su tierra llamado Huacayñán, y que después de pasado el Diluvio y acabándose la vitualla que allí habían recogido, salían por el contorno a buscar de comer, dejando sola su morada, que era una pequeña choza que habían hecho para albergarse. Sustentándose de raíces y hierbas, pasaron por algún tiempo grandes necesidades y hambre, mas, volviendo un día a su choza quebrados de cansancio, la hallaron muy abastecida de diversos manjares y abundancia de chicha, sin saber de dónde ni quién les hubiese hecho tan notable beneficio y regalo. Quedaron muy admirados de esto, buscaron con diligencia si aparecía por allí alguien, con deseo de saber de cuya mano eran socorridos en tiempo de tanta apretura, y no hallando rastro de gente, se asentaron a comer y mataron el hambre por entonces. De esta manera pasaron diez o doce 
días, hallando siempre proveído de comidas el rancho como el primer día. Al cabo de este tiempo, curiosos de ver y conocer a quien les hacía tanto bien, acordaron que el uno se quedase escondido en casa, y para esto hicieron un hoyo en la parte más oscura de ella, en el que se metió el uno, y el otro se fue a su ejercicio del campo. En este tiempo vio el que estaba en centinela entrar por la puerta dos guacamayas, que luego que estuvieron dentro se transformaron en dos hermosas mujeres Pallas, que es tanto como notables de sangre real, ricamente vestidas del traje que hoy usan las mujeres cañares (...) Quitándose las llicllas, que son sus mantos, ellas empezaron a aderezar de comer de lo que traían. El mancebo salió en esto de su escondite, saludándolas cortésmente, comenzó a trabar conversación con ellas; las cuales entonces alborotadas y turbadas de que las hubiesen visto, sin responderle palabra, se salieron de prisa de la casa, y vueltas en su primera forma de guacamayas, se fueron volando sin hacer ni dejar este día ninguna comida. El mozo, cuando se halló solo, viendo que no le había salido el lance como deseaba, se comenzó a afligir y lamentar, maldiciendo su fortuna. Estando en esta congoja, llegó del campo el otro hermano, y sabido el suceso, le riñó con enojo y cólera, motejándole de cobarde y hombre sin brío ni valor, pues había perdido tan grande ocasión. En fin, se determinaron de quedarse ambos escondidos en su casa, por ver si volvían las guacamayas. Ellas, al cabo de tres días, volvieron como solían, y entrando por la puerta, tomaron forma humana, apareciendo dos bellas doncellas, y empezaron a poner en orden la comida. Los mozos, que estaban en acechanza, habiéndolas dejado antes acabar el quehacer, salieron de improviso y cerrándoles la puerta, sin preceder cortesía alguna, se abrazaron con ellas, a las cuales no dio lugar la turbación a tomar su figura de aves. Comenzaron con enojo y despecho a dar gritos y hacer fuerzas para soltarse, pero los mancebos, al fin con halagos y palabras amorosas la aplacaron y aquietaron; y cuando las vieron sosegadas, les rogaron ahincadamente les contasen su progenie y linaje y la causa de venirles a hacer aquel beneficio. Ellas, ya pacíficas y tratables, les respondieron que Ticciviracocha les había mandado hacer aquel misterio, socorriéndoles en aquel conflicto, porque no pereciesen de hambre. En conclusión, ellas se quedaron por esposas de los dos mancebos, y de la sucesión que dejaron afirman haberse poblado aquella provincia de los cañares..."

Por último, los relatos de este orden correspondientes al Área Mesoaméricana -en los que el animal originario de "la misteriosa ama de casa" es invariablemente un perro o una perra- muestran contenidos de similitud tan acusada, que conducen a pensar en la posibilidad, ya sugerida por Horcasitas (ibídem, 202-203), de que se trate de un relato único que en una época no determinada se difundió desde le centro del territorio mexicano hacia las zonas costeras, que son las áreas de donde provienen las versiones hasta hoy registradas.

Las procedencias y fuentes de las once versiones relativas a esta Área del Continente, son las siguientes:

- Versiones hicholes: v.1: Anguiano y Furts (1978/1987: 30-32); v.2: Gonzáles Torres (1991: 66); v.3: Carl Lumholtz (en: Horcasitas, ibídem.: 204); v.4: K. Th. Preuss (en: Horcasitas, ibídem.: 204); v.5: Robert Mowry Zingg (en: Horcasitas, ibídem.: 204); v.6. 
Jon Mc Intosh (en: Horcasitas, ibídem.: 204-205).

- Versión tepecana: J. Alden Mason (en: Horcasitas, ibídem.: 205).

- Versiones totonacas: v.1: Manuel Oropeza Castro (en: Horcasitas, ibídem.: 205-206); v.2: F. Horcasitas, (ibídem.: 206).

- Versiones tlapanecas: v.1: H.V. Lemley (en: Horcasitas, ibídem.: 206); v.2: Id. (en: Horcasitas, ibídem. : 206).

Con el propósito de no reseñar los contenidos, en gran medida reiterados, de estas versiones, expondremos a continuación -y transcrito en cursiva- el que en nuestro criterio es el desarrollo esquemático del relato tipo, anotando entre paréntesis las variantes más significativas correspondientes a las seis versiones huicholes (abreviadas, H.) y la versión tepecana (abreviada, T.). Este relato tipo, y con él sus variantes, lo confrontaremos luego con las versiones totonacas y tlapanecas.

* Un hombre (H.: v.1: Watákame; v.2,5: kauymali; v.4: Timusave) observa una mañana que los árboles y la maleza que había cortado el día anterior han vuelto a crecer durante la noche. Descubre que esto lo ha causado una anciana (H.: v.1: la bisabuela Nawaké; v.2: Nawaké; v.3: la abuela Nawaké; v.4: Tahutai Nawaké; T.: un anciano), quien le dice que no trabaje más, ya que se avecina un diluvio. Le dice además que fabrique una caja (H.: v.2,4: que ahueque un árbol; v.5,6: que haga una canoa; T.: que construya un arca) y que se meta en ella con alimentos y una perra (H.: v.1,2,3,4: con una perra negra; $T$.: no la menciona). Llega el diluvio. (H.: v.2: durante cinco años el árbol (v.3: la caja) flota a la deriva; T.: durante cuarenta días el arca flota a la deriva) Cuando las aguas bajan, el hombre abandona su refugio y en compañía de la perra, vuelve a trabajar. Sin embargo, cada vez que regresa a su casa encuentra que alguien le ha preparado tortillas (H.: v.6 y T.: comida). Se pone a vigilar y descubre que la perra se quita la piel y transformada en una mujer, prepara las tortillas. Entonces se aproxima sigilosamente (H.: v.4,5: mientras la mujer está lavando en el río; v.6: cuando la mujer va en busca de agua al río) y arroja la piel al fuego, provocando que la mujer grite de dolor (H.: v.3: se queje; v.6: se lamente como un perro). Para calmarla, el hombre la baña con agua de nixtamal (H.:v.2,4: no se menciona este episodio). Transformada para siempre en mujer, ella se queda como esposa del hombre (...vv...) y ambos procrean muchos hijos (H.: v.1: que son los antepasados de los huicholes; v.2: que son los mexicanos) que repueblan el mundo.

Las versiones totonacas (v.1 y v.2) y tlapanecas (v.1 y v.2) que completan las manifestaciones del motivo en este tipo de relatos, se atienen en lo general al desarrollo aquí expuesto, omitiendo, empero, determinados episodios. De esta manera, ninguna de estas cuatro versiones contiene el incidente del baño con agua de nixtamal, en tanto que la segunda versión totonaca omite también la quema de la piel. A su vez, ambas versiones totonacas y la primera versión tlapaneca carecen del pasaje inicial referente a la vegetación misteriosamente crecida, episodio 
que sí se encuentra en la segunda versión tlapaneca, la cual finaliza cuando el hombre arroja al fuego la piel de la perra. También cabe señalar que la segunda versión totonaca es la que más se aparta del relato tipo en lo que se refiere a su desenlace. Para ilustrar esta afirmación, citamos a continuación el final de esta versión:

Un día, él se ocultó y descubrió que la perra se quitaba la piel en un tamazcal y luego le preparaba alimentos. Él la siguió y la atrapó. La perra dijo: "Dios así lo quiere. Ahora estaremos casados y tendremos hijos". Ellos repoblaron el mundo.

Ya en el cierre de la revisión de los relatos de este tipo originados en Mesoamérica sólo resta hacer una breve referencia a dos elementos de sus contenidos que han merecido comentarios de distintos investigadores. Estos elementos son: la presencia de la perra como especie que da origen a "la misteriosa ama de casa" que inicia el repoblamiento del mundo, y el episodio del baño de agua de nixtamal que se reitera en las versiones hicholes y tlapaneca.

En relación con el primero de estos elementos, conviene anotar, siguiendo a Wigberto Jiménez Moreno (cit. en Horcasitas, ibídem.: 208), que el término "chichimecas" (literalmente 'linaje del perro'), aplicado a los pueblos asentados en el extremo noroeste de México y que dieron origen a los toltecas, se deriva del animal totémico identificado con la perra del mito del diluvio. Así, según lo señalan Anguiano y Furst (ibídem.: 32), "Muchos de los pueblos chichimecas comparten con los hicholes una tradición similar de descendencia del perro" .

Precisamente este pretendido origen, que motivaba que los totlteca-chichimecas fueran rechazados por otros pueblos vecinos, se vincula con el segundo de los elementos señalados al afirmar Jiménez Moreno, en otro lugar de la mencionada cita, que siendo los tolteca-chichimecas cautivos de los olmec-xicalanca, estos los humillaban arrojándoles a la cara "agua de nixtamal", en clara referencia a su origen perruno.

\section{Distribución geográfica de las funciones del motivo de "la misteriosa ama de casa" en los distintos órdenes de relatos y de los elementos más relevantes que concurren en el desarrollo de este episodio}

Con el propósito de ofrecer en relación con su distribución geográfica, una exposición sinóptica de las funciones del motivo de "la misteriosa ama de casa" en los tipos de relatos especificados, así como de los principales elementos que se reiteran en las versiones consideradas, hemos acudido a la presentación de mapas que muestran la procedencia de cada uno de estos aspectos . El detalle de estos mapas es el siguiente: 


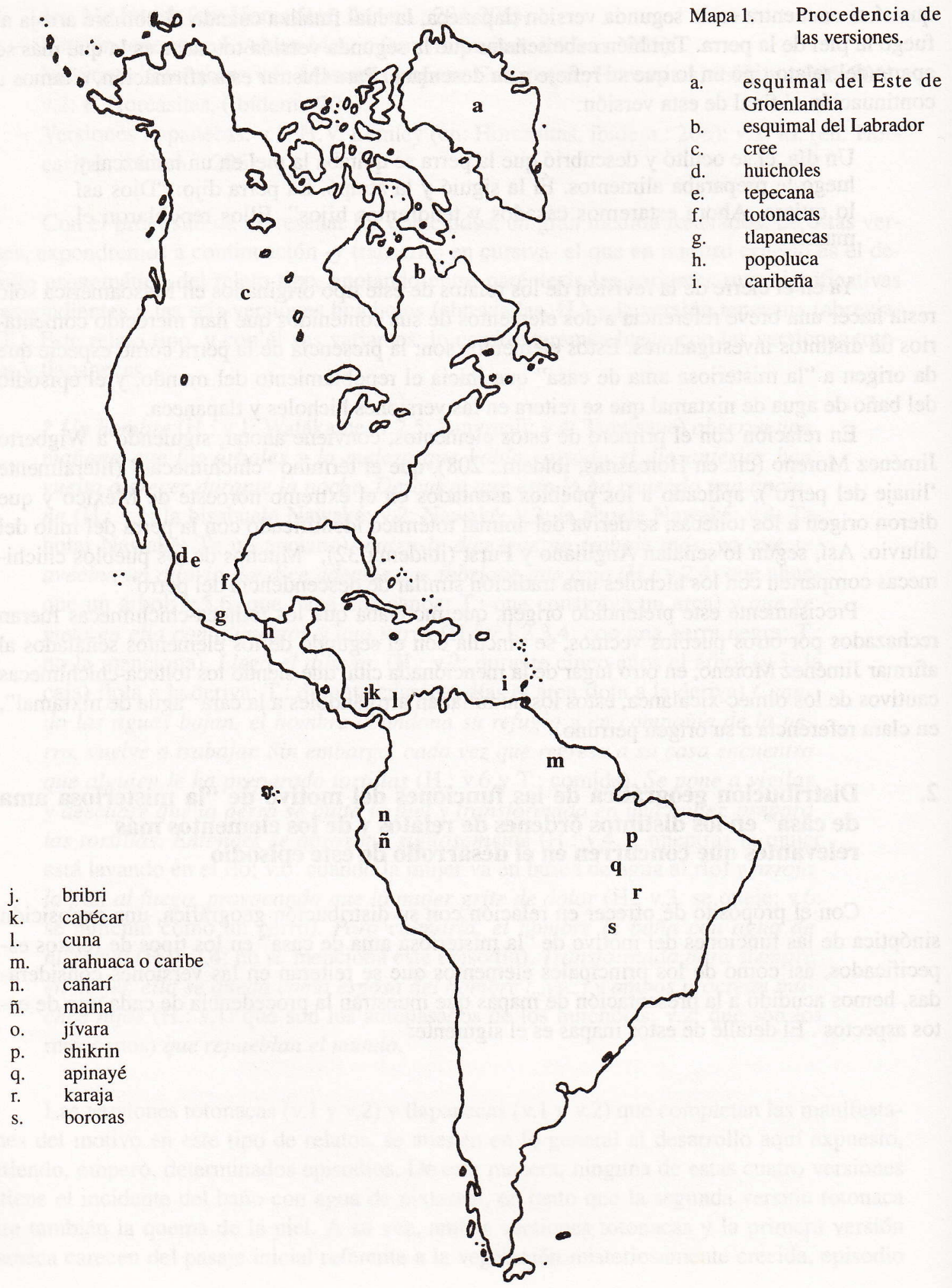




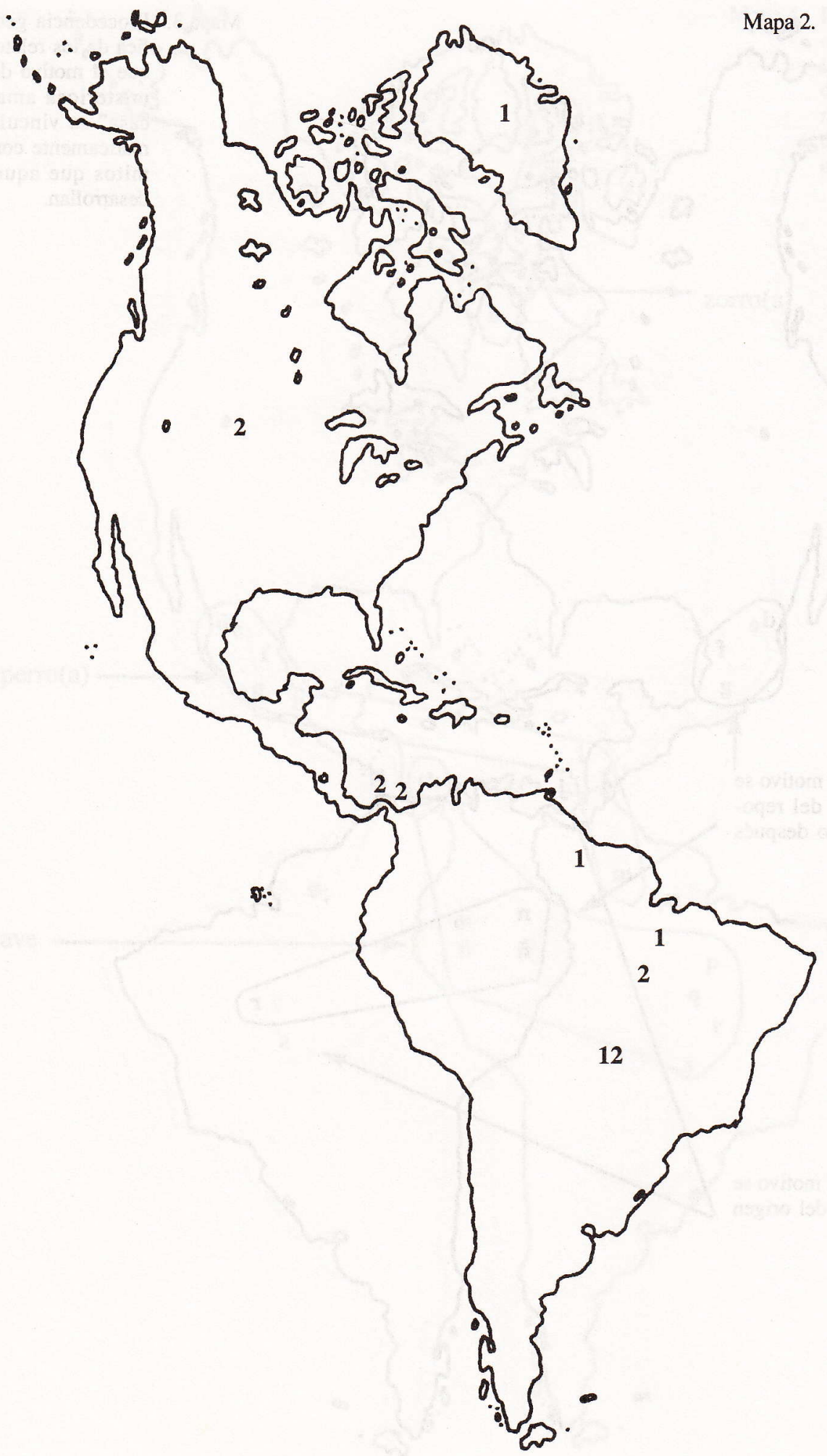

Funciones del motivo de "la misteriosa ama de casa" en dos tipos de relatos: 1 relatos que reducen su contenido al desarrollo del motivo; 2. relatos en los que el motivo es un fragmento no vinculado temáticamente con los distintos mitos que aquellos desarrollan. 


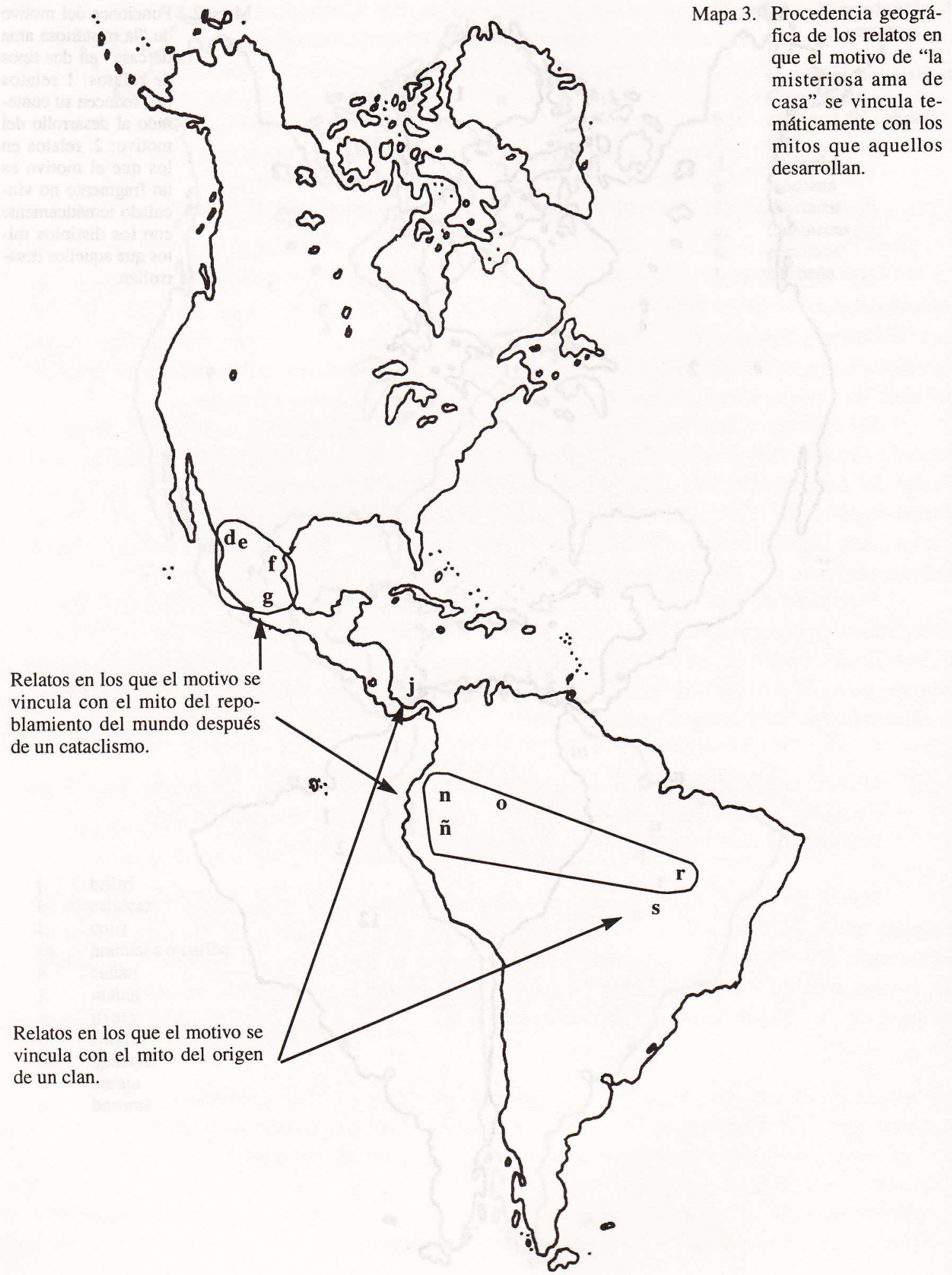




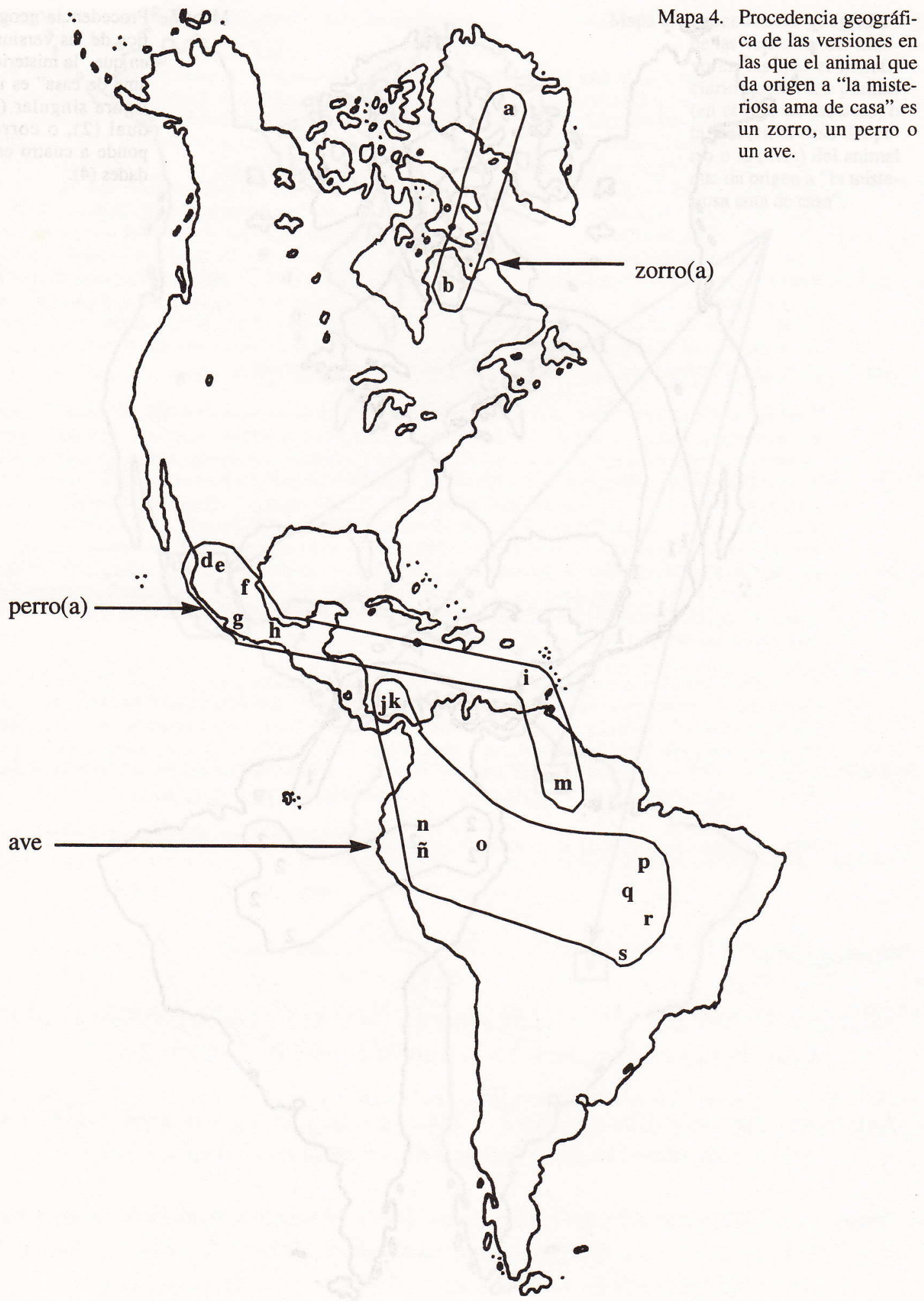


126

REVISTA DE FILOLOGIA Y LINGÜISTICA

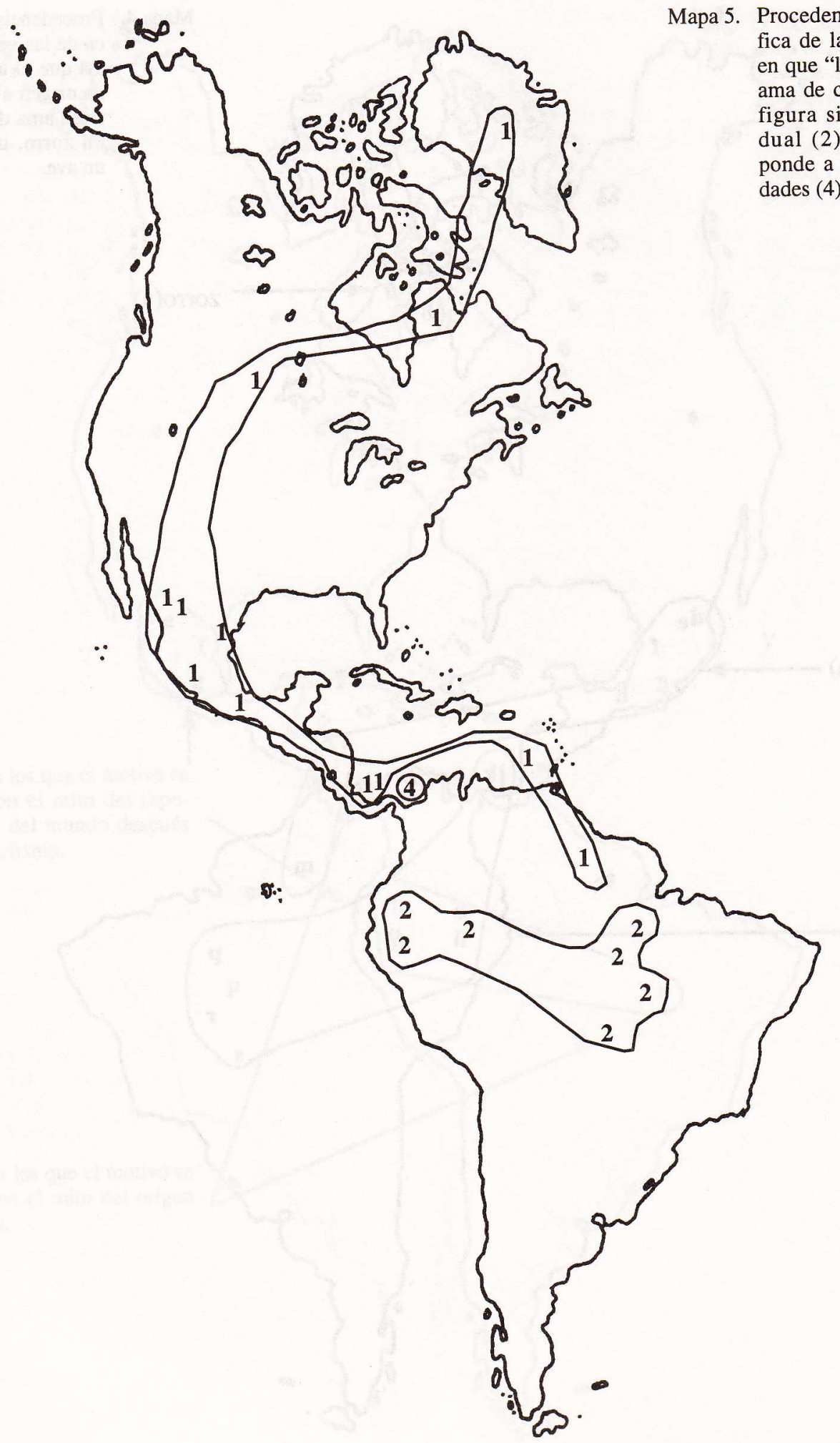




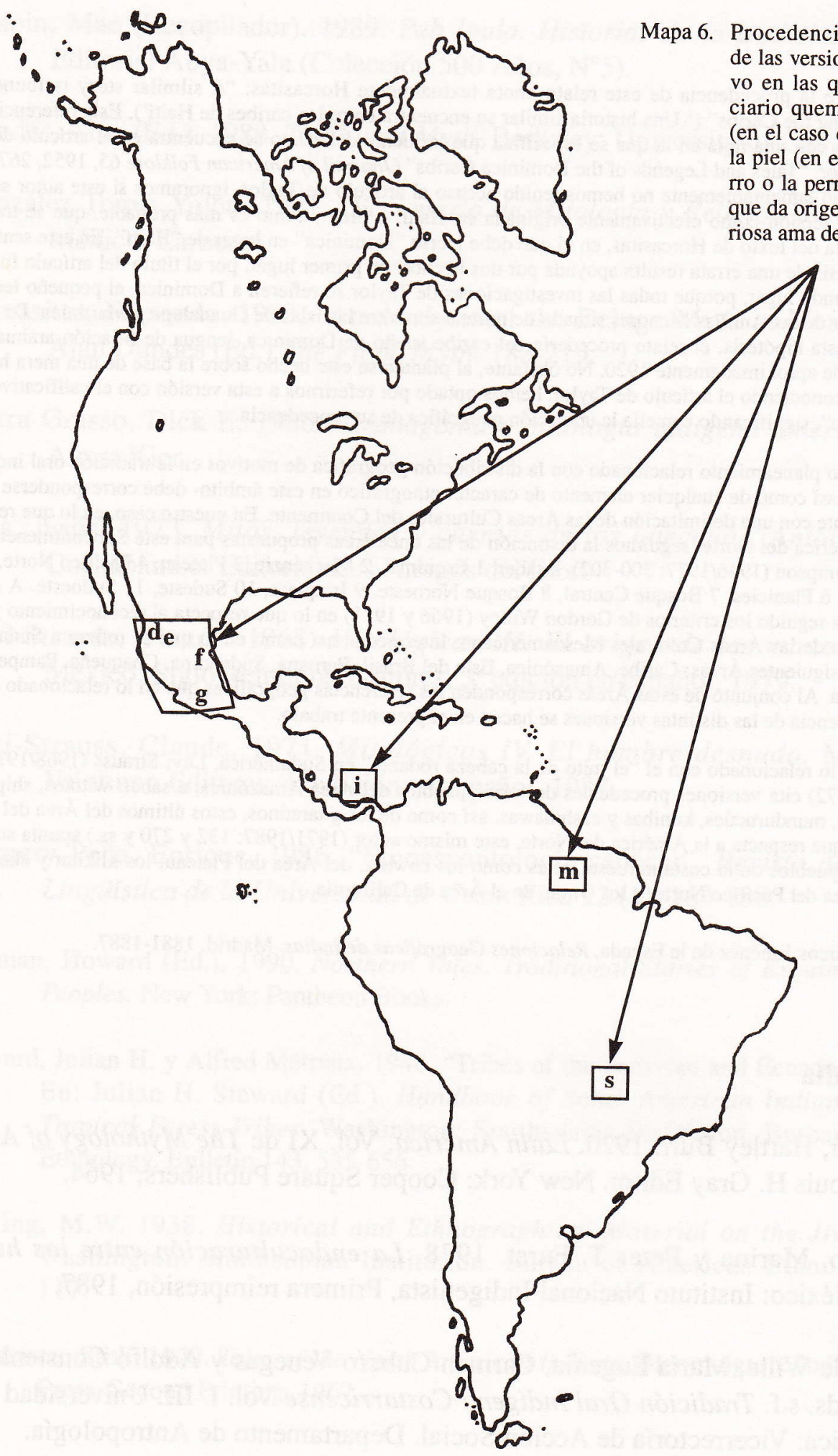




\section{Notas}

1. Sobre la procedencia de este relato anota textualmente Horcasitas: "A silmilar story is found in Haiti among the Caribs" ("Una historia similar se encuentra entre los caribes de Haití'). Esta referencia se completa con una nota en la que se especifica que la fuente del relato se encuentra en el artículo de Douglas Taylor, "Tales and Legends of the Dominica Caribs" (Journal of American Folklore 65, 1952, 267-269). Como lamentablemente no hemos tenido acceso al artículo de Taylor, ignoramos si este autor se refiere a esta versión como efectivamente originada en Haití, o bien, como es más probable, que se trate de una errata del texto de Horcasitas, en el que debe leerse "Dominica" en lugar de "Haitr". En este sentido, la hipótesis de una errata resulta apoyada por dos hechos: en primer lugar, por el título del artículo fuente, y, en segundo lugar, porque todas las investigaciones de Taylor se refieren a Dominica, el pequeño territorio insular de las Antillas Menores situado de norte a sur entre las islas de Guadalupe y Martinica. De ser efectiva esta hipótesis, el relato procedería del caribe isleño de Dominica, lengua de filiación arahuaca extinta desde aproximadamente 1920. No obstante, al plantearse este hecho sobre la base de una mera hipótesis, y desconociendo el artículo de Taylor, hemos optado por referirnos a esta versión con el calificativo de "caribeña", significando con ella la ubicación geográfica de su procedencia.

2. Todo planeamiento relacionado con la distribución geográfica de motivos en la tradición oral indoamericana -así como de cualquier elemento de caracter etnográfico en este ámbito- debe corresponderse necesariamente con una delimitación de las Areas Culturales del Continente. En nuestro caso, en lo que respecta a la América del Norte, seguimos la distinción de las once áreas propuestas para este Subcontinenete por Stith Thompson (1946/1977: 300-302), a saber: 1 Esquimal, 2 Mackenzie, 3 Plateau, 4 Pacífico Norte, 5 California, 6 Planicies, 7 Bosque Central, 8 Bosque Noroeste, 9 Iroquesa, 10 Sudeste, 11 Sudoeste. A su vez, hemos seguido los criterios de Gordon Willey (1966 y 1971) en lo que respecta al reconocimiento y delimitación de las Áreas Culturales Mesoamericana, Intermedia, así como en lo que se refiere a Sudamérica, de las siguientes Áreas: Caribe, Amazónica, Este del Brasil, Peruana, Sudandina, Chaqueña, Pampeana y Fuegina. Al conjunto de estas Áreas corresponden las referencias geográficas que en lo relacionado con la procedencia de las distintas versiones se hacen en el presente trabajo.

3. En lo relacionado con el "el mito de la cabeza rodante" en Sudamérica, Lévi Strauss (1968/1979: 37-39 y 70-72) cita versiones procedentes de varios pueblos del Area Amazónica, a saber: witotos, shipayas, tembés, mundurucúes, kunibas y cashinawas, así como de los guaraúnos, estos últimos del Área del Caribe. En lo que respecta a la América del Norte, este mismo autor (1971/1987: 132 y 270 y ss.) apunta su existencia en pueblos de la costa noroeste, tales como los cowlitz, del Área del Plateau; los klikitat y chehalis, en el Área del Pacífico Norte, y los wintu, en el Área de California.

4. Marcos Jiménez de la Espada, Relaciones Geográficas de Indias. Madrid, 1881-1887.

\section{Bibliografía}

Alexander, Hartley Burr. 1920. Latin America. Vol. XI de The Mythology of All Races, Louis H. Gray Editor. New York: Cooper Square Publishers, 1964.

Anguiano, Marina y Peter T. Furst. 1978. La endoculturación entre los huicholes. México: Instituto Nacional Indigenista, Primera reimpresión, 1987.

Bozzoli de Wille, María Eugenia, Carmen Cubero Venegas y Adolfo Constenla Umaña Eds. s.f. Tradición Oral Indígena Costarricense Vol. I. III. Universidad de Costa Rica: Vicerrectoría de Acción Social. Departamento de Antropología. 
Chapin, Mac (Recopilador). 1989. Pab Igala. Historias de la tradición Kuna. Quito: Editorial Abya-Yala (Colección 500 Años, №5).

Dundes, Alan (Ed.). 1988. The Flood Myth. Berkeley: University of California Press.

González Torres Yoloti. 1991. Diccionario de Mitología y Religión de Mesoamérica. México: Larousse.

Horcasitas, Fernando. 1953. "An Analysis of the Deluge Myth in Mesoamerica”. En Alan Dundes (Ed.) The Flood Myth: 183-219.

Ibarra Grasso, Dick E. 1980. Cosmogonía y mitología indígena americana. Buenos Aires: Kier.

Lara, Jesús, 1973, Mitos, leyendas y cuentos de los quechuas. Antología. La PazCochabamba: Editorial Los Amigos del Libro.

Lévi-Strauss, Claude. 1968. Mitológicas III. El origen de las maneras de mesa. México: Siglo Veintiuno Editores, $3^{a}$ edición en español, 1979.

Lévi-Strauss, Claude. 1971. Mitológicas IV. El hombre desnudo. México: Siglo Veintiuno Editores, $4^{a}$ edición en español, 1987.

Margery Peña, Enrique. 1986. "Etnoespantología cabécar". Revista de Filología y Lingüística de la Universidad de Costa Rica 22 (1): 163-188.

Norman, Howard (Ed.). 1990. Northern Tales. Traditional Stories of Esquimo and Indian Peoples. New York: Pantheon Books.

Steward, Julian H. y Alfred Métraux. 1948. "Tribes of the peruvian and Ecuadorian Montana". En: Julian H. Steward (Ed.). Handbook of South American Indians. Vol.3. The Tropical Forest Tribes. Washington: Smithsonian Institution. Bureau of American Ethnology. Bulletin 143, 535-656.

Stirling, M.W. 1938. Historical and Ethnographical Material on the Jivaro Indians. Washington: Smithsonian Institution. Bureau of American Ethnology. Bulletin 117.

Thompson, Stith. 1929. Tales of the North American Indians. Bloomington: Indiana University Press, Second Printing, 1967. 
Thompson, Stith. 1946. The Folktale. Berkeley and Los Angeles: University of California Press. 1977.

Wilbert, Johannes y Karin Simoneau (Eds.). 1978. Folk Literature of the Gê Indians. Vol. One. Los Angeles: UCLA Latin American Center Publications.

Wilbert, Johannes y Karin Simoneau (Eds.). 1983. Folk Literature of the Bororo Indians. Los Angeles: UCLA Latin American Center Publications.

Wilbert, Johannes y Karin Simoneau (Eds.). 1984. Folk Literature of the Gê Indians. Vol. Two. Los Angeles UCL.A Latin American Center Publications.

Willey, Gordon R. 1966. An Introduction to American Archaeology. Vol.I. North and Middle America. Englewood Cliffs, Nueva Jersey: Prentice Hall Inc.

Willey, Gordon R. 1971. An Introduction to American Archaeology. Vol.II. South America. Englewood Cliffs, Nueva Jersey: Prentice Hall Inc. 